\title{
Associated factors of REM sleep without atonia in younger ( $\leq 50$ years) hospitalized psychiatric patients
}

\author{
Jitka Bušková ${ }^{1,2^{*}}$ (D), Eva Miletínová ${ }^{1,2}$, Monika Kliková ${ }^{1,2}$, Martin Bareš ${ }^{1,2}$, Tomáš Novák ${ }^{1,2}$, Jiřina Kosová1,2,
} Pavla Stopková ${ }^{1,2}$ and Jana Koprivová ${ }^{1,2}$

\begin{abstract}
Background: Isolated REM sleep without atonia (RSWA) as a main polysomnograhic feature of REM sleep behaviour disorder (RBD) is thought to be a prodromal or subclinical state of the disease. RSWA/RBD occurence in psychiatric population is much more frequent than in general population but its associated factors are still not known.

Methods: We invited 88 psychiatry in-patients to undervent video-polysomnography. The visual scoring was focused on RSWA in submentales and flexores digitales superficiales muscles. This parametr was subsequently correlated mainly with age/gender, their medication and mental status.

Results: The RWSA was mostly still in normal range despite the fact, that selected psychiatry patients ( $\leq 50$ years) were taking several classes of psychoactive medication. 3,6\% had convincingly RBD, although $35.7 \%$ reported rare lifetime occurence of dream-enacting behaviour and $62.8 \%$ sporadic nightmares. We found correlation between RSWA and SNRI medication class $(p=0.015)$, specifically venlafaxine $(p=0.029)$ as well as quetiapine $(p=0.030)$. Another significant associated factors were current anxiety $(p<0.001)$ and depressive symptoms $(p=0.05)$, but we found no relation between RSWA and given diagnosis.
\end{abstract}

Conlucions: Isolated RSWA in younger psychiatry patients might be a result of multiple factors, including medication and current mental status but these factors are in most cases not sufficient to manifest RBD.

Keywords: REM sleep without atonia, REM sleep behaviour disorder, Psychiatric patients, Antidepressants, Antipsychotics, Anxiety, Depression

\section{Background}

REM sleep without atonia (RSWA) is defined as excessive sustained or intermittent elevation of chin electromyographic (EMG) tone or excessive phasic chin or limb EMG twitching [1]. Together with dream-enacting behaviour (DEB) RSWA is a key polysomnograhic feature of REM sleep behaviour disorder

\footnotetext{
* Correspondence: vankjit@seznam.cz

'Department of Sleep Medicine, National Institute of Mental Health, Topolová 748, 25067 Klecany, Czech Republic

${ }^{2}$ Third Faculty of Medicine, Charles University, Prague, Czech Republic
}

(RBD). Two major clinical aspects are important in RBD. Firstly, the nocturnal behaviour may result in severe injuries for the patient or his/her bed partner. Secondly, the idiopathic form of RBD represents an early-stage of $\alpha$-synucleinopathy [2,3], which emphasizes timely recognition of the disease, especially in terms of future neuroprotective therapy. Isolated RSWA is hypothesized to be a prodromal or subclinical phase of RBD, but its relevance is still unknown, especially in psychiatric population.

(c) The Author(s). 2020 Open Access This article is licensed under a Creative Commons Attribution 4.0 International License, which permits use, sharing, adaptation, distribution and reproduction in any medium or format, as long as you give appropriate credit to the original author(s) and the source, provide a link to the Creative Commons licence, and indicate if changes were made. The images or other third party material in this article are included in the article's Creative Commons licence, unless indicated otherwise in a credit line to the material. If material is not included in the article's Creative Commons licence and your intended use is not permitted by statutory regulation or exceeds the permitted use, you will need to obtain permission directly from the copyright holder. To view a copy of this licence, visit http://creativecommons.org/licenses/by/4.0/ The Creative Commons Public Domain Dedication waiver (http://creativecommons.org/publicdomain/zero/1.0/) applies to the data made available in this article, unless otherwise stated in a credit line to the data. 
There is some evidence that RBD in psychiatric patients is much more frequent than in the general population [4, 5]. Likewise, there are several studies showing close association of RBD/RSWA with psychiatric illness or with antidepressant use [5-8]. However, there is still ongoing controversy over whether $\mathrm{RBD}$ in psychiatric patients is one of the separate subgroups of RBD patients, and if so, if it is solely related to the effects of mental illness per se or antidepressants, or to the combination of both factors /other clinical factors $[6,7,9,10]$.

The main aims of our study were 1) to find out if isolated RSWA depends on age and gender in psychiatric patients; or wheather another clinical factors might play a role, 2) to delineate the influence of medication, given diagnosis and current mental stutus on the degree of RSWA. According to the presumption that RSWA could be induced by the use of antidepressants, especially SSRI/SNRI [6, 8, 11-14], we hypothesized that the RSWA would be more prominent on this medication classes compared to other medical classes and will be more distinct in patients with severe psychiatric symptoms, independently of age and gender.

\section{Methods}

\section{Subjects}

Psychiatric in-patients hospitalized for 6-8 weeks between June 2018 and December 2019 at the National Institute of Mental Health, CZ, were invited to participate in this prospective polysomnography study. At the day of video-polysomnography (v-PSG), all of them completed the BDI-II [15] and BAI [16] questionnnaires. They underwent clinical examinations by a neurologist and a psychiatrist in order to exclude any disease that could be potentially associated with RBD, such as narcolepsy, dementia and Parkinson's disease. Along with sociodemographic data (age, gender, education), we documented sleep comorbidities (that were consequently confirmed by video-polysomnography). All the patients were specifically asked about dream-enacting behaviour and nightmares. From other clinical factors, history taking at the day of v-PSG, was specifically focused on their family history of mental illness and perinatal history, autoimmune disease and smoking/alcohol/drugs use. Given psychiatric diagnosis and the use of psychoactive medications was listed.

\section{Video-polysomnography}

Nocturnal video-polysomnography (v-PSG) was performed using a digital Brainscope PSG system and consisted of 19-channel electroencephalography (EEG), electrooculography (EOG), electromyography of the bilateral mentalis muscle, the bilateral flexor digitorum superficialis muscle (FDS) and the bilateral tibialis anterior muscle (TA), electrocardiography, nasal pressure, nasal and oral air flow, thoracic and abdominal respiratory effort, oxygen saturation, microphone and synchronized video monitoring from 10 p.m. to 6 a.m. according to the recommendation by the American Academy of Sleep Medicine (AASM) [1]. All of the features were analysed visually. Sleep stages, arousals, respiratory events, and limb movements were scored according to the AASM Manual for the Scoring of Sleep and Associated Events, version 2.22015 (Scoring Manual 2007) $[1,17]$ with an exception for the REM sleep rules allowing to score REM sleep stage despite the prominent EMG activity in the mentalis muscle channel [18]. The occurence of the first rapid eye movements (REMs) in the EOG channel was used to determine the onset of particular REM sleep period. The end of each REM sleep period was determined when either no REMs were detected in 3 consecutive minutes or awakening or $\mathrm{K} \mathrm{com-}$ plexes or sleep spindles were observed.

We only included subjects with $>5$ min of REM sleep. RSWA was scored in the submentalis muscle and bilateral FDS channels in 1-s mini-epochs. All artefacts and increases in EMG tone due to arousals from respiratory events, periodic limb movements (PLM) events and any kind of arousal-related movement were excluded as much as possible from the quantitative scoring before the analysis of EMG activity. RSWA was visually scored in 30s epochs: either increased tonic activity, defined as an increase of $>50 \%$ in baseline EMG amplitude (measured during nonREM sleep) or $>10 \mu \mathrm{V}$ during $>50 \%$ of REM epoch, or increased phasic activity, defined as all muscle activity during $0,1-5 \mathrm{~s}$ that exceeded 4 times the background EMG activity in $1 \mathrm{~s}$-mini-epochs within a 30s REM epoch. Each 1-s mini-epoch was scored as having or not having "any" EMG activity, irrespective of containing phasic or tonic EMG activity. After scoring any EMG activity in the submentalis muscle channels, we scored the EMG activity in the FDS channels in 1-s mini-epochs not having any EMG activity already scored in the submentalis muscle channels. Thus, we obtained an overall score expressing the percentage of disturbed muscle tone in REM sleep referring to the total amount of REM sleep-related EMG activity (RSWA \%). We did not quantify REM sleep behavioural events and we did not established specific cut-off for RBD.

The study was approved by the local Ethics Committee. All of the patients signed the informed consent before inclusion in the study.

\section{Statistical analysis}

Descriptive parameters, such as demographic data, frequency of particular diagnosis and types of medication were calculated for particular variables of interest. After testing for normality by using Shapiro-Wilk test, we used 
non-parametric correlations and Kruskal-Wallis test for comparing multiple groups. All of the tests were conducted by using SPSS-23 program.

\section{Results}

From 120 invited psychiatry in-patients, total of 88 agreed to participate in the study. We excluded 8 patients because of the records' artefacts (biologicalmuscle, respiratory, ECG or technical), 12 records for obstructive sleep apnoea $(\mathrm{AHI} \geq 15)$ and 10 periodic limb movements in sleep (PLMI $\geq 15$ ) mimicking RBD or not allowing for the evaluation of muscle tone in REM sleep, and 2 records with REM sleep under $5 \mathrm{~min}$. Finaly, 56 patients $(42 \mathrm{~F} / 14 \mathrm{M}$, mean age 38.25 , age range $26-$ 50 years) were included in our study. The Table 1 describes polysomnographic findings in all patients. In these recordings we evaluated REM sleep muscle tone. The mean isolated RSWA was $8.77 \%, \mathrm{SD}=9.23$. This was a baseline for all the planned analysis. Two patients (3.6\%) actually passed the criteria for RBD (with prominent dream-enacting behavior on video-polysomnography and with the percentage of disturbed muscle tone in REM sleep to be 32.5 and 55\%). In the other patients we did not capture DEB immediately on videopolysomnography, but $35.7 \%$ reported lifetime occurence of DEB (rare/once or twice a life) and $68.2 \%$ refered nightmares. We did not find any correlation between age/gender and total RSWA\%.

From other clinical characteristics, 7 patients (12.5\%) were smokers, smoking between 10 and 40 cigarettes per day, 49 (87.5\%) were never daily smoker. 36 (64.3\%) were occasional drinkers, but they did not drink while being on the psychoactive medication except of 4

Table 1 Polysomnography parameters of psychiatry patients

\begin{tabular}{ll}
\hline Variable & Psychiatric patients $(\boldsymbol{n}=\mathbf{5 6})$ \\
\hline TST (min) & $359(\mathrm{SD}=85.78)$ \\
SOL (min) & $30.60(\mathrm{SD}=24.86)$ \\
SE \% & $85.62(\mathrm{SD}=6.78)$ \\
WASO \% & $14.36(\mathrm{SD}=10.37)$ \\
NREM 1\% & $5.5(\mathrm{SD}=5.60)$ \\
NREM 2\% & $47.79(\mathrm{SD}=10.15)$ \\
NREM 3\% & $17.57(\mathrm{SD}=8.22)$ \\
AHI & $9.16(\mathrm{SD}=9.09)$ \\
PLMI & $12.45(\mathrm{SD}=11.03)$ \\
REM \% & $14.78(\mathrm{SD}=6.67)$ \\
REM latency & $172.35(\mathrm{SD}=72.58)$ \\
REM periods & $2-5$ \\
RSWA \% & $8.77(\mathrm{SD}=9.23)$
\end{tabular}

Legend: TST total sleep time, SOL sleep onset latency, SE sleep efficiency, WASO wake after sleep onset, NREM non-REM sleep, AHI apnoea-hypopnoea index, $P L M I$ periodic limb movement index, REM rapid eye movement sleep, RSWA REM sleep without atonia individuals. None of our patients confessed regular alcohol abuse. Patients did not report any recent or ongoing substance abuse. We found autoimmune diseases in 12 (21.4\%) of our patients, 8 of them had Hashimoto's thyroiditis, 2 psoriasis, 1 diabetes mellitus type I, 1 rheumatoid arthritis. In 8 (14.3\%) of the patients we found positive perinatal history (6 of them reported asfyxia, two were born premature). Most of our patients achieved at least secondary school education level, 19 (33.9\%) of them had BC degree or above, 33 (58.9\%) finished secondary school and only 4 (7.1\%) of our participants finished only a primary school. Considering the fact that our patients often planned to continue their education proces after finishing the treatment and due to a small sample size in one of our groups it was rather difficult to stratify them based on the highest level of education they achieved so far. The last factor of interest was family history of psychiatric disease. We found such disease in 18 cases (32.1\%) in mother (1x dementia, 3x anxiety disorder, $12 \mathrm{x}$ depression, $2 \mathrm{x}$ alcohol abuse), 15 times $(26.8 \%)$ in father (2x depression, $13 x$ alcohol abuse), 12x (21.4\%) in siblings (5x anxiety disorder, $5 \mathrm{x}$ depression, $2 \mathrm{x}$ alcohol). None of these clinical factors significantly influenced REM-sleep muscle activity.

\section{RSWA and medication}

Table 2 shows patients' medication in detail. 19 (33.9\%) patients were currently on SSRI (selective serotonin reuptake inhibitors), 15 (26.8\%) on SNRI (selective norepinephrine reuptake inhibitors), 9 (16.1\%) on NaSSA (noradrenergic and specific serotonergic antidepressants), $14(25 \%)$ on antipsychotics and $13(23.2 \%)$ on mood stabilizers. $8(14.28 \%)$ of the patients were prescribed anxiolytics, but they were taken only ad hoc and not 3 day before polysomnography. None of them was on Z-drugs. Four patients (7.1\%) took no antidepressant treatment. Fifteen patients $(26.8 \%)$ were on 1 category of medication, $23(41.1 \%)$ patients were on 2 catagories of medication and $14(25 \%)$ were on 3 classes. The more categories of antidepressants were taken, the higher the total amount of disturbed muscle atonia. However, this trend was not statistically significant (Spearman's rho = 0.226, $p=0.093$ ).

We analyzed potential correlations between the use of particular classes of medication and the degree of muscle atonia disruption. We did not find any significant correlation between RSWA\% and the use of SSRI as a class as well as for particular drugs. However, we found a moderate positive correlation between SNRI use and degree of disturbed muscle atonia (Spearman's rho = $0.332, p=0.015$ ).

Some relationship was also found between use of particular type of medication and RSWA \%. There was a weak positive correlation between use of venlafaxine and 
Table 2 Psychoactive medication

\begin{tabular}{|c|c|c|c|}
\hline Medication class & Medication name & \# cases & Doses (mg) \\
\hline \multicolumn{4}{|l|}{ Antidepressants } \\
\hline \multirow[t]{6}{*}{ SSRI } & Escitalopram & 8 & $10-30$ \\
\hline & Sertralin & 5 & $100-300$ \\
\hline & Citalopram & 3 & $10-40$ \\
\hline & Fluoxetine & 2 & 60 \\
\hline & Paroxetine & 1 & 40 \\
\hline & & Total 19 & \\
\hline SNRI & Venlafaxine & 15 & $150-300$ \\
\hline SARI & Trazodone & 16 & $50-300$ \\
\hline \multirow[t]{2}{*}{ NaSSA } & Mirtazapine & 6 & $15-45$ \\
\hline & Mianserin & 3 & $30-60$ \\
\hline \multirow[t]{3}{*}{ Other ADs } & Vortioxetine & 1 & 10 \\
\hline & Agomelatine & 5 & $25-50$ \\
\hline & & Total 46 & \\
\hline \multicolumn{4}{|l|}{ Antipsychotics } \\
\hline FGA & Chlorprotixen & 1 & $15-30$ \\
\hline \multirow[t]{4}{*}{ SGA } & Quetiapine & 10 & $100-400$ \\
\hline & Olanzapine & 2 & $2,5-10$ \\
\hline & Aripiprazol & 1 & 15 \\
\hline & & Total 14 & \\
\hline \multicolumn{4}{|l|}{ Anticonvulsants } \\
\hline \multirow[t]{2}{*}{ Mood stabilizers } & Lamotrigine & 5 & $100-300$ \\
\hline & Valproate & 3 & $1000-1500$ \\
\hline \multirow[t]{2}{*}{ Other AEs } & Pregabaline & 5 & $75-450$ \\
\hline & & Total 13 & \\
\hline
\end{tabular}

Legend: SSRI selective serotonin re-uptake inhibitors, SNRI selective noradrenalin re-uptake inhibitors, SARI serotonin antagonists and reuptake inhibitors, NaSSA noradrenergic and specific serotoninergic antidepressants, $A D$ antidepressants, FGA first generation antipsychotics, SGA second generation antipsychotics, $A E$ anitepileptics

RSWA\% (Spearman's rho $=0.292, p=0.029$ ) and quetiapin (Spearman's rho $=0.289, p=0.030$ ). Other correlations were not significant or were not to be proved due to a small sample sizes.

\section{RSWA and psychiatric diagnoses}

We devided the patients' cohort into groups according to diagnoses. The precise list of diagnoses and their frequencies in our cohort can be found in Table 3. Thirty-five patients (62.5\%) were diagnosed with mood disorder, 21 (37.5\%) with anxiety disorder and $12(21.4 \%)$ with personality disordes, that was typically the second diagnose. Four patients (7.1\%) had a history of psychoactive substance abuse (2 alcohol, 1 benzodiazepine, 1 cocaine). We found no statistically significant correlation between specific diagnose and RSWA\%.
Table 3 Psychiatric diagnoses

\begin{tabular}{ll}
\hline Psychiatric diagnoses & \# cases \\
\hline PRIMARY DIAGNOSES & \\
Mood disorders & 27 \\
$\quad$ Recurrent depressive disorder & 6 \\
Bipolar disorder & 2 \\
Dysthymia & Total 35 \\
Anxiety disorders & \\
Obsessive-compulsive disorder & 5 \\
Panic disorder & 5 \\
Posttraumatic stress disorder & 4 \\
Generalized anxiety disorder & 4 \\
Phobic anxiety disorder & 3 \\
& Total 21 \\
COMORBID conDITIONS & \\
Personality disorders & 12 \\
Substance abuse & 4 \\
Eating disorders & 2 \\
\hline
\end{tabular}

\section{Current mental status}

At BAI, 34 patients (60.7\%) scored above 15 (moderate/ severe anxiety) and at BDI 33 patients (58.9\%) scored $\geq 19$ (moderate/severe depression). We found a strong positive correlation between BAI and RSWA\% (Spearman's rho $=0.879, p<0.001$ ), and weak positive correlation between BDI and RSWA\% ( $\mathrm{p}=$ Spearman's rho = $0.263, p=0.05)$.

\section{Discussion}

We found the degree of REM sleep atonia in younger ( $\leq$ 50 years) psychiatry patients to be very variable, ranging from very low to high degree of impairment. According the literature, there were several cut-offs established from different muscles included in the measurement [19-23]. We quantified the RSWA from mm. submentales and flexores digitorum superficiales, that would be most similar to SINBAR methods with estimated cut-off of $32 \%$ of REM sleep [19, 24]. If we applied this cut-off, we had 2 cleary defined RBD cases in our group of patients, but many other (35.7\%) refered rare lifetime occurence of DEB that was not captured on v-PSG or occasional nightmares (62.8\%). The occurence of DEB and RSWA were not always associated which could lead to false positive RBD diagnosis. Repeating the v-PSG to visualize both RSWA and DEB might be preferred for RBD diagnosis. We decided to score RSWA in 1-sminiepochs instead of commonly used scoring criteria, because we believed that this strategy would be more exact and more appropriate in this specific cohort with highly supressed REM sleep. 


\section{RSWA and age/gender, other clinical factors}

The mean age of our participants was 38 years (age range between 26 and 50 years), with higher proportion of females. This could be due to more frequent psychiatric diagnoses in women, and also due to exclusion of 8 men suffering from obstructive sleep apnoea. This however, emphasasis the fact, that RSWA frequently occurs in young women, which is in line with currently available data, that describe relatively high occurrence of early onset RSWA/RBD in women [25], even suggesting a unique clinical profile of the condition. Patients who were diagnosed as early onset RBD were mainly female gender with significantly more past and ongoing psychiatric disorders and use of antidepressants [5]. Many of such patients are also middle-aged women suffering from autoimmune disease [11]. Nevertheless, other studies report different outcomes, finding no difference in RBD between male and female in middle-to-older general population [26] or even slight male predominance in patients under 50 years of age [27]. RBD is often thought to be under-recognised in women due to more subtle presentation [28]. The evidence is still inconclusive as it was also suggested that female subjects suffering from RBD present with comparable clinical features and prevalence of sleep-related injuries [29]. We did not find any association between increased RSWA\% and age in our group of patients.

We found no significant difference in education level, but it was not possible to stratify this cohort much, because the majority of our patients had secondary school or higher education, with only 4 (7.1\%) patients with completed primary education. The fact, that our patients did not report the use or abuse of alcohol could have been biased by participants'possible tendency to confirm that they follow the recomendations regarding the use of psychoactive medication and alcohol consumption, which is not recomended in any case. Thus, we could argue that some patients intentionally lowered their daily alcohol consumption. We did not confirm this assumption by providing any objective alcohol levels testing. Due to patients'long term stay in ward the possibility of their ongoing alcohol intake was very low.

Only 1 patient had past history of benzodiazepine abuse, 2 patients of alcohol and one of cocaine abuse. Literature shows that one of the RBD-subgroups can be middle-aged women with autoimmune disease [11], but we did not find any association between RSWA and history of autoimmune disease in our patients' cohort, as well as in positive perinatal history or family history of mental diseases [30]. Because other studies confirm several risk factors for RBD in general population [26, 31], we hypothesized that it could reflect the epidemiological heterogeneity of RSWA/RBD.

\section{RSWA and medication}

Concerning psychoactive medication, numerous drugs, including fluoxetine, venlafaxine, mirtazapine, paroxetine, clomipramine or sertraline, as well as antidepressants as a group, have been associated with exacerbation of RSWA/RBD [8, 12, 13, 32-34]. In their retrospective study, Winkelman and James described higher frequency of RSWA (RBD was not specifically assessed) in subjects taking serotonergic antidepressants compared to controls [8]. After withdrawal of SSRI the authors did not observe a complete resolution of clinical RBD symptoms and PSG abnormalitis [6, 32]. On the other hand, some RBD cases have been successfully treated with certain antidepressants [35] and withdrawal from certain antidepressants such as imipramine induced acute RBD [36]. Another study found no difference in atonia index between RBD patients taking or not antidepressants [37]. Moreover, some recent studies point out that also antipsychotics may play a role $[26,38]$ suggesting that dopaminergic modulation can influence RBD/RSWA.

Our patients typically took several antidepressants from different classes, that made it difficult to determine specific associations. Moreover, many of our patients were hospitalized because the only one medication (typically from SSRI class) did not have adequate effect on the severity of their psychiatric symptoms, and the cross-titration with SNRI was provided, that means that they were on relatively low doses. Nevertheless, we saw some trend in higher RSWA in patients who were on several psychoactive categories of medication and specificaly on SNRI and antipsychotics. According to the literature we expected higher RSWA also after current SSRI use, but likely, serotoninergic system alone is not enough to cause dysregulation of REM sleep atonia, and more profound and complex dysfunction of monoaminergic systems might be needed in order to cause clinically visible symptoms. Some evidence shows that the sole effect of SSRI agents is not convincing. A clinical epidemiological study conducted in a psychiatric outpatient setting found that the risk of developing RBD among those taking SSRI antidepressants was only 1 out of 20 [4] and another study suggests that serotoninergic system is not directly involved in the pathogenesis of RBD, even though an increased serotoninegic tone could unveil acute RBD in predisposed subjects $[39,40]$. The noradrenergic system might also be involved in RBD pathogenesis [41] since noradrenergic antagonist drugs have been reported to induce RBD [42]. Our results suggest a complex interplay of different neurotransmitter systems including serotonin, noradrenalin and dopamin intervening in REM-on/REM-off balance. However, methodological issues could play a role, as several 
studies that confirmed the effect of SSRI were based on measurements of RSWA from mm. tibiales muscles, in contrast to our study $[8,12]$.

\section{RSWA and psychiatric diagnosis}

Finaly, there is an ongoing controversy regarding the relationship between psychiatric illness itself as an etiological factor in RBD. Several studies showed potential relationship between RBD and severe stress or posttraumatic stress disorder (PTSD) [43-45]. It has been hypothesized that repeated traumas increase noradrenaline turnover, leading to its depletion in the LC, which in turn exerts an inhibitory action on the cholinergic laterodorsal tegmental LDT nucleus, tj. LC dysfunction might underlie both these disorders [43]. The evidence is however limited. Other studies did not find any clinically significant sleep disorder or typical pattern of sleep disturbance detectable by standard polysomnography in PTSD patients [46].

Wing et al. suggests that depression is a significant risk factor in predicting PD in iRBD patients [47]. On the other hand, McCarter claims that antidepressants but not depression appears to have a mediating role in promoting RSWA, given that only patients taking antidepressants had significantly higher muscle activity than psychiatric patients who are not treated with antidepressants [13]. Our results showed that more than given diagnoses, the actual mental state was important for patients' RSWA\%.

\section{RSWA and mental state}

We found a positive correlation between BAI/BDI and REM sleep without atonia in our cohort of psychiatric patients. Lam et al. even described that psychiatric RBD patients had higher scores over BDI and HADS anxiety subscale (near statistical significance), HADS anxiety subscale showed significant difference between psychiatric and typical RBD cases [48]. Another study came with similar findings, declaring significantly more prominent symptoms of depression and anxiety in psychiatry RBD patients with higher Hospital Anxiety and Depression Scale and Beck Depression Inventory [49]. They claim, that there could be other individual susceptibility and clinical factors that increase the risk of developing RBD symptoms upon the onset of psychiatric illnessess and usage of antidepressants.

There are some limitations that could be mentioned. First is small number of cases on individual antidepressant agents. Unfortunatelly obtaining bigger sample size was not possible in our hospitalized psychiatric patients as they typically needed potent or multiple treatment. None of our patients presented motor or cognitive abnormalities during neurological examination. However, other biomarkers such as autonomic and specific sensory testings were not provided. Unfortunately, our results should also be interpreted with regard to the fact that we are not able to provide data obtained from control group.

In terms of RSWA assessment, 1-s miniepoch RSWA scoring may be a limitation for comparisons between studies. Nevertheless, we believe that in this specific sample with highly supressed REM sleep scoring in 3-s miniepochs could falsely increase the percentage of disturbed muscle atonia. Our patients underwent only one night in sleep laboratory, thus we could not underpin eventuall night-to-night variability in REM sleep atonia. Moreover, as we did not analyze the activity of anterior tibialis muscle, we are not able to confront our findings with current normative data for adult [50]. This would still be difficult as the authors of the study excluded patients who were receiving antidepressant medication during the time of the study. To our knowledge, normative data for psychiatric cohort are still missing.

\section{Conclusions}

Isolated REM sleep without atonia in younger psychiatry patients is associated with psychoactive medication as well as current mental status, more that given diagnoses, but these factors are in most cases not sufficient to cause RBD. Further follow-up studies are needed to clarify whether current mental state, antidepressant use or other underlying factors might precipitate full-blown RBD. It is also not possible to apply the abovementioned findings to older aged patients with RBD. Our findings indicate the heterogeneity of RBD spectrum disease. It also has many important public health implications since antidepressants are among the most commonly prescribed medications, and physicians should be aware of the potential for RSWA and subsequent injurious dream-enactment behaviours associated with these medications.

\section{Abbreviations \\ AASM: American Academy of Sleep Medicine; AHI: Apnoea-hypopnoea index; BAI: Beck anxiety inventory; BDI-II: Beck depression inventory, second version; DEB: Dream-enacting behaviour; ECG: Electrocardiography; EEG: Electroencephalography; EMG: Electromyography; \\ EOG: Electrooculography; FDS: Flexor digitorum superficialis muscle; LC: Locus coeruleus; LDT: Laterodorsal tegmentum nucleus; OSA: Obstructive sleep apnoea; PLMI: Periodic limb movements index; PLMS: Periodic limb movements in sleep; PTSD: Post-traumatic stress disorder; RBD: REM sleep behaviour disorder; REM: Rapid eye movement sleep; REMP: REM period; RSWA: REM sleep without atonia; SSRI/SNRI: Selective serotonin/noradrenalin re-uptake inhibitors; TA: Tibialis anterior muscle; v-PSG: Video- polysomnography}

\section{Acknowledgments}

This study was supported by project Nr. LO1611 from the MEYS under the NPU I program and by Charles University under grant Progres Q35 and 260533/SW/2020. 


\section{Authors' contributions}

JB: research project: conception; design; execution; review; manuscript preparation: writing of the first draft; review and critique. EM: research project: conception; design; statistical analysis; review and critique; manuscript preparation: review and critique. MK: research project: organization; execution; review and critique; manuscript preparation: review and critique. RK: research project: execution; manuscript preparation: review and critique. MB: research project: organization; conception; review and critique; manuscript preparation: review and critique. TN: research project: conception; design; review and critique; manuscript preparation: review and critique. JKos: research project: organization; conception; review and critique; manuscript preparation: review and critique. PS: research project: organization; conception; review and critique; manuscript preparation: review and critique. JKop: research project: organization; conception; review and critique; manuscript preparation: review and critique. All authors have read and approved the manuscript.

\section{Funding}

The authors received no specific funding for this work.

\section{Availability of data and materials}

The datasets used during the current study are available from the corresponding author on reasonable request.

\section{Ethics approval and consent to participate}

This study is approved by NIMH Research Ethics Board, Klecany, Czech Republic. Written informed consent is obtained from all participants prior to any study related activities.

\section{Consent for publication}

Not applicable.

\section{Competing interests}

The authors declare that they have no competing interests.

Received: 16 April 2020 Accepted: 19 September 2020

Published online: 01 October 2020

\section{References}

1. Berry RB, Brooks R, Gamaldo C, Harding SM, Lloyd RM, Quan SF, et al. AASM scoring manual updates for 2017 (version 2.4). J Clin Sleep Med. 2017;13(5): 665-6.

2. Postuma RB, Iranzo A, Hu M, Hogl B, Boeve BF, Manni R, et al. Risk and predictors of dementia and parkinsonism in idiopathic REM sleep behaviour disorder: a multicentre study. Brain. 2019;142(3):744-59.

3. Dauvilliers Y, Schenck CH, Postuma RB, Iranzo A, Luppi PH, Plazzi G, et al. REM sleep behaviour disorder. Nat Rev Dis Primers. 2018;4(1):19.

4. Lam SP, Fong SY, Ho CK, Yu MW, Wing YK. Parasomnia among psychiatric outpatients: a clinical, epidemiologic, cross-sectional study. J Clin Psychiatry. 2008;69(9):1374-82.

5. Teman PT, Tippmann-Peikert M, Silber MH, Slocumb NL, Auger RR Idiopathic rapid-eye-movement sleep disorder: associations with antidepressants, psychiatric diagnoses, and other factors, in relation to age of onset. Sleep Med. 2009;10(1):60-5.

6. Lam SP, Zhang J, Tsoh J, Li SX, Ho CK, Mok V, et al. REM sleep behavior disorder in psychiatric populations. J Clin Psychiatry. 2010;71(8):1101-3.

7. Wing YK, Lam SP, Tsoh JM, Mok VC. Rapid eye movement sleep behaviour disorder and psychiatry: a case-control study. Hong Kong Med J. 2015; 21(Suppl 6):34-8.

8. Winkelman JW, James L. Serotonergic antidepressants are associated with REM sleep without atonia. Sleep. 2004;27(2):317-21.

9. Lam SP, Li SX, Mok V, Wing YK. Young-onset REM sleep behavior disorder: beyond the antidepressant effect. Sleep Med. 2012;13(2):211.

10. Lam SP, Zhang J, Wing YK. REM sleep behavior disorder: from epidemiology to heterogeneity. Sleep. 2013;36(8):1117-9.

11. Ju YE, Larson-Prior L, Duntley S. Changing demographics in REM sleep behavior disorder: possible effect of autoimmunity and antidepressants. Sleep Med. 2011;12(3):278-83.

12. Zhang B, Hao Y, Jia F, Tang Y, Li X, Liu W, et al. Sertraline and rapid eye movement sleep without atonia: an 8-week, open-label study of depressed patients. Prog Neuro-Psychopharmacol Biol Psychiatry. 2013;47:85-92.
13. McCarter SJ, St Louis EK, Sandness DJ, Arndt K, Erickson M, Tabatabai G, et al. Antidepressants increase REM sleep muscle tone in patients with and without REM sleep behavior disorder. Sleep. 2015;38(6):907-17.

14. Lee K, Baron K, Soca R, Attarian $\mathrm{H}$. The prevalence and characteristics of REM sleep without atonia (RSWA) in patients taking antidepressants. J Clin Sleep Med. 2016;12(3):351-5.

15. Beck AT, Steer RA, Ball R, Ranieri W. Comparison of beck depression inventories -IA and -II in psychiatric outpatients. J Pers Assess. 1996;67(3): 588-97.

16. Beck AT, Epstein N, Brown G, Steer RA. An inventory for measuring clinical anxiety: psychometric properties. J Consult Clin Psychol. 1988; 56(6):893-7.

17. Berry RB, Gamaldo CE, Harding SM, Brooks R, Lloyd RM, Vaughn BV, et al. AASM scoring manual version 2.2 updates: new chapters for scoring infant sleep staging and home sleep apnea testing. J Clin Sleep Med. 2015;11(11): 1253-4.

18. Schenck CH, Mahowald MW. Rapid eye movement sleep parasomnias. Neurol Clin. 2005;23(4):1107-26.

19. Frauscher B, Iranzo A, Gaig C, Gschliesser V, Guaita M, Raffelseder V, et al. Normative EMG values during REM sleep for the diagnosis of REM sleep behavior disorder. Sleep. 2012;35(6):835-47.

20. Montplaisir J, Gagnon JF, Fantini ML, Postuma RB, Dauvilliers Y, Desautels A, et al. Polysomnographic diagnosis of idiopathic REM sleep behavior disorder. Mov Disord. 2010;25(13):2044-51.

21. Gagnon JF, Postuma RB, Montplaisir J. Update on the pharmacology of REM sleep behavior disorder. Neurology. 2006;67(5):742-7.

22. Zhang J, Lam SP, Ho CK, Li AM, Tsoh J, Mok V, et al. Diagnosis of REM sleep behavior disorder by video-polysomnographic study: is one night enough? Sleep. 2008;31(8):1179-85.

23. Consens FB, Chervin RD, Koeppe RA, Little R, Liu S, Junck L, et al. Validation of a polysomnographic score for REM sleep behavior disorder. Sleep. 2005; 28(8):993-7.

24. Frauscher B, Ehrmann L, Hogl B. Defining muscle activities for assessment of rapid eye movement sleep behavior disorder: from a qualitative to a quantitative diagnostic level. Sleep Med. 2013;14(8):729-33.

25. Zhou J, Zhang J, Li Y, Du L, Li Z, Lei F, et al. Gender differences in REM sleep behavior disorder: a clinical and polysomnographic study in China. Sleep Med. 2015:16(3):414-8.

26. Haba-Rubio J, Frauscher B, Marques-Vidal P, Toriel J, Tobback N, Andries D, et al. Prevalence and determinants of REM sleep behavior disorder in the general population. Sleep. 2017.

27. Bonakis A, Howard RS, Ebrahim IO, Merritt S, Williams A. REM sleep behaviour disorder (RBD) and its associations in young patients. Sleep Med. 2009:10(6):641-5.

28. Bodkin CL, Schenck CH. Rapid eye movement sleep behavior disorder in women: relevance to general and specialty medical practice. J Women's Health (Larchmt). 2009;18(12):1955-63.

29. Wing YK, Lam SP, Li SX, Yu MW, Fong SY, Tsoh JM, et al. REM sleep behaviour disorder in Hong Kong Chinese: clinical outcome and gender comparison. J Neurol Neurosurg Psychiatry. 2008;79(12):1415-6.

30. Liu Y, Zhang J, Lam SP, Zhou J, Yu MWM, Li SX, et al. A case-control-family study of idiopathic rapid eye movement sleep behavior disorder. Ann Neurol. 2019:85(4):582-92.

31. Yao C, Fereshtehnejad SM, Keezer MR, Wolfson C, Pelletier A, Postuma RB. Risk factors for possible REM sleep behavior disorder: a CLSA populationbased cohort study. Neurology. 2018.

32. Schenck CH, Mahowald MW, Kim SW, O'Connor KA, Hurwitz TD. Prominent eye movements during NREM sleep and REM sleep behavior disorder associated with fluoxetine treatment of depression and obsessivecompulsive disorder. Sleep. 1992;15(3):226-35.

33. Onofrj M, Luciano AL, Thomas A, lacono D, D'Andreamatteo G. Mirtazapine induces REM sleep behavior disorder (RBD) in parkinsonism. Neurology. 2003;60(1):113-5.

34. Parish JM. Violent dreaming and antidepressant drugs: or how paroxetine made me dream that I was fighting Saddam Hussein. I Clin Sleep Med. 2007;3(5):529-31.

35. Takahashi T, Mitsuya H, Murata T, Murayama J, Wada Y. Opposite effects of SSRIs and tandospirone in the treatment of REM sleep behavior disorder. Sleep Med. 2008;9(3):317-9.

36. Schenck CH, Hurwitz TD, Mahowald MW. REM sleep behavior disorder. Am J Psychiatry. 1988;145(5):652. 
37. Ferri R, Arico D, Cosentino FIl, Lanuzza B, Chiaro G, Manconi M. REM sleep without atonia with REM sleep-related motor events: broadening the spectrum of REM sleep behavior disorder. Sleep. 2018;41(12):zsy187.

38. Tan L, Zhou J, Liang B, Li Y, Lei F, Du L, et al. A case of quetiapine-induced rapid eye movement sleep behavior disorder. Biol Psychiatry. 2016;79(5): e11-e2.

39. Arnaldi D, Fama F, De Carli F, Morbelli S, Ferrara M, Picco A, et al. The role of the serotonergic system in REM sleep behavior disorder. Sleep. 2015; 38(9):1505-9.

40. Postuma RB, Gagnon JF, Tuineaig M, Bertrand JA, Latreille V, Desjardins C, et al. Antidepressants and REM sleep behavior disorder: isolated side effect or neurodegenerative signal? Sleep. 2013;36(11):1579-85.

41. Peever J, Luppi PH, Montplaisir J. Breakdown in REM sleep circuitry underlies REM sleep behavior disorder. Trends Neurosci. 2014;37(5):279-88.

42. Iranzo A, Santamaria J. Bisoprolol-induced rapid eye movement sleep behavior disorder. Am J Med. 1999;107(4):390-2.

43. Husain AM, Miller PP, Carwile ST. Rem sleep behavior disorder: potential relationship to post-traumatic stress disorder. J Clin Neurophysiol. 2001; 18(2):148-57.

44. Ross RJ, Ball WA, Dinges DF, Kribbs NB, Morrison AR, Silver SM, et al. Motor dysfunction during sleep in posttraumatic stress disorder. Sleep. 1994;17(8): 723-32

45. Ross RJ, Ball WA, Dinges DF, Kribbs NB, Morrison AR, Silver SM, et al. Rapid eye movement sleep disturbance in posttraumatic stress disorder. Bio Psychiatry. 1994;35(3):195-202.

46. Hurwitz TD, Mahowald MW, Kuskowski M, Engdahl BE. Polysomnographic sleep is not clinically impaired in Vietnam combat veterans with chronic posttraumatic stress disorder. Biol Psychiatry. 1998;44(10):1066-73.

47. Wing YK, Li SX, Mok V, Lam SP, Tsoh J, Chan A, et al. Prospective outcome of rapid eye movement sleep behaviour disorder: psychiatric disorders as a potential early marker of Parkinson's disease. J Neurol Neurosurg Psychiatry. 2012;83(4):470-2.

48. Lam SP, Li SX, Chan JW, Mok V, Tsoh J, Chan A, et al. Does rapid eye movement sleep behavior disorder exist in psychiatric populations? A clinical and polysomnographic case-control study. Sleep Med. 2013;14(8): 788-94.

49. Wing YK, Lam SP, Mok VC, Zhang J, Tsoh JM, Leung EY. Early neurodegenerative biomarkers and clinical outcome in psychiatric patients with rapid eye movement sleep behaviour disorder: a prospective study. Hong Kong Med J. 2018;24(3):24-8.

50. Feemster JC, Jung Y, Timm PC, Westerland SM, Gossard TR, Teigen LN, et al. Normative and isolated rapid eye movement sleep without atonia in adults without REM sleep behavior disorder. Sleep. 2019;42(10):zsz124.

\section{Publisher's Note}

Springer Nature remains neutral with regard to jurisdictional claims in published maps and institutional affiliations.

Ready to submit your research? Choose BMC and benefit from:

- fast, convenient online submission

- thorough peer review by experienced researchers in your field

- rapid publication on acceptance

- support for research data, including large and complex data types

- gold Open Access which fosters wider collaboration and increased citations

- maximum visibility for your research: over $100 \mathrm{M}$ website views per year

At $\mathrm{BMC}$, research is always in progress.

Learn more biomedcentral.com/submissions 